\title{
Stress in the surface layer of objects burnished after milling
}

\author{
Daniel Grochała $\cdot$ Stefan Berczyński • Zenon Grządziel
}

Received: 1 September 2013 / Accepted: 10 March 2014 /Published online: 30 March 2014

(C) The Author(s) 2014. This article is published with open access at Springerlink.com

\begin{abstract}
This paper presents the effects of modeling the stress in the burnished layer of a complex spatial surface that was previously milled. A spatial kinematicgeometric model of the surface structure after milling is used. This paper presents the results of a numerical experiment on the synergic influence of the technological milling and burnishing parameters responsible for the final state of the geometric structure of a surface on the post-machining stress in the surface layer. The stress in the surface layer plays an important role because it is frequently responsible for the development of cracks, corrosion, and cavitation (in the surface area of injection aluminum molds, press tools, and core cutters). A proper understanding of the mechanisms responsible for the origin and development of residual stress will be conducive to the improvement of functional properties and longer tool life.
\end{abstract}

\footnotetext{
D. Grochała $(\bowtie) \cdot$ S. Berczyński

Institute of Mechanical Technology, West Pomeranian University of Technology Szczecin, Szczecin, Poland

e-mail: daniel.grochala@zut.edu.pl

S. Berczyński

e-mail: stefan.berczynski@zut.edu.pl

D. Grochała $\cdot$ S. Berczyński

Faculty of Mechanical Engineering and Mechatronics, Institute of Manufacturing Engineering, West Pomeranian University of

Technology, Aleja Piastów 19, 70-310 Szczecin, Poland

\section{Z. Grządziel}

Institute of Fundamental Engineering Sciences, Maritime University

of Szczecin, Szczecin, Poland

e-mail: z.grzadziel@am.szczecin.pl

Z. Grządziel

Department of Mechanical Engineering, Institute of Fundamental

Sciences and Technology, Maritime University of Szczecin, ul. Podgórna 51/53, 70-205 Szczecin, Poland
}

Keywords Ball burnishing $\cdot$ 3D burnishing model $\cdot$ Residual stress $\cdot$ Roughness topography

\section{Introduction}

The design of modern technological processes aims at achieving higher quality for the final product, shortening the processing time, and cutting the costs. It is only possible to meet the above goals by bringing together various technological processes into one operation.

Burnishing is a common form of machining and is often integrated with cutting, particularly when machining a rotating work piece on a lathe, drill, or boring machine. The burnishing tool runs then parallel to traces left by the cutting tool (tool bit, drill, boring bar). Recently, burnishing has been used more frequently in machining centers for the finish operations for complex spatial surfaces [1-10]. By combining shape milling and finish burnishing in one operation, there are many more possibilities for connecting the trajectories of the tools, from parallel $[7,8]$ to perpendicular $[2,4,9]$.

The rule of thumb of machining operations is to achieve a desired geometric structure for the surface defined by particular requirements for the texture, roughness, reflexivity, and stress in the surface layer. There are usually no problems with obtaining the required smoothness effects. The literature contains many models for shaping the required roughness, depending on the tool, theoretical machining parameters, or initial geometric structure of the surface. One model usually considers one particular case of machining. For roughness modeling purposes, we use experimental data [2,3], analytical models [1], artificial intelligence algorithms [11], and most commonly the finite element method (FEM) [12-14]. While being very consistent with experimental data for the surface geometry, FEM modeling can determine the residual stress that remains on the surface of a workpiece. It is a hard task to 


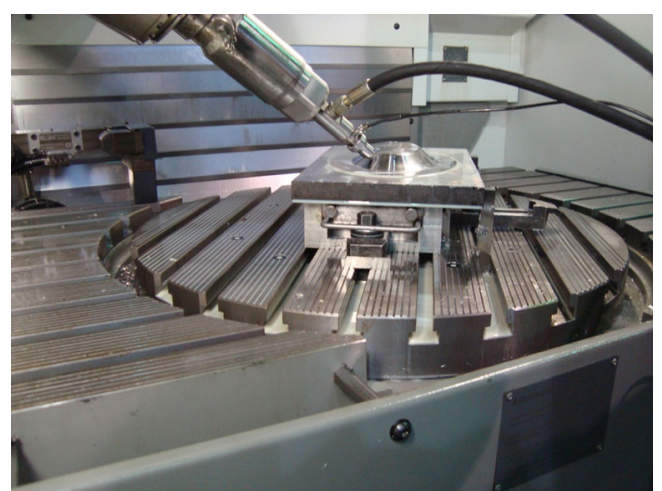

Fig. 1 Normal position of hydraulic burnishing tool with integrated force gauge during 3D surface machining on five-axis machining center DMG DMU 60 MONOBLOCK [2]

model the surface geometry and residual stress after burnishing because excessive simplification of a model may be distorted by errors in the FEM numerical calculations. Although a detailed 3D simulation of surface burnishing makes it possible to determine the mechanisms involved in the formation of roughness irregularities, stress shaping, and surface geometry improvement, it requires substantial computational power and time [12]. The literature most commonly presents the results of numerical experiments conducted for 2D FEM models. It is possible to minimize the computational force requirements. Additionally, a numerical experiment can cover a wider range of variables (ball diameter, burnishing speed and force, initial roughness of surface, number of passes, etc.) $[15,16]$. The results of studies using 2D FEM models are easy to validate experimentally. To this end, lathe turning samples can be burnished [3, 6, 13, 15]. Methods based on indirect microhardness measurements are used to determine the residual stress [3]. More recently, X-ray diffraction methods have also been applied [2, 6, 14].

\section{Burnishing of complex spatial surfaces}

The burnishing of complex spatial surfaces with hydraulic single-ball burnishing tools on multi-axis machining centers yields very good surface roughness effects $[2,4,5]$. It is possible to burnish constantly improved heat-treated steel with a high hardness, even above 50 HRC [2, 4]. Large surface sections are treated while burnishing injection molds of matrices and press tools. Therefore, it is crucial to make an optimal selection of technological parameters for both processing operations to ensure the required roughness and high efficiency [1, 7, 9]. Previous studies [4-6] showed that the burnishing speed has an insignificant effect on the final roughness. Thus, it is recommended to conduct machining at the maximum feed rates available at a machining center. The force of burnishing has the greatest influence on the final effect of the treatment [2], regardless of the initial roughness after milling. It is important to maintain a constant burnishing force [9]. The easiest way of achieving this condition is to set up the tool in the normal position vs. the workpiece (Fig. 1).

A previous study [2] presented the results of milling surfaces with various values of parameter cross feed $\left(f_{w}\right)$ (Fig. 3), as a result of which a different roughness value was achieved in each case (Fig. 2). Samples were then burnished with various values of force $F_{N}$. When $F_{N} \geq 1,000 \mathrm{~N}$, the roughness in each case was $\mathrm{Ra} \approx 0.12 \mu \mathrm{m}$.

Once all the samples were burnished, a homogenous surface was obtained. Except for force $\left(F_{N}\right)$, the technological parameters of the finish burnishing were the same in each case, and the burnishing times did not differ significantly. However, the milling times were significantly different (a seven-fold reduction in the main time when milling with $f_{w}=0.7$, instead of $f_{w}=0.1$ ).

\section{The roughness surface relationship between ball burnishing force and milling parameters - for steel 42CrMo4 (35HRC)}

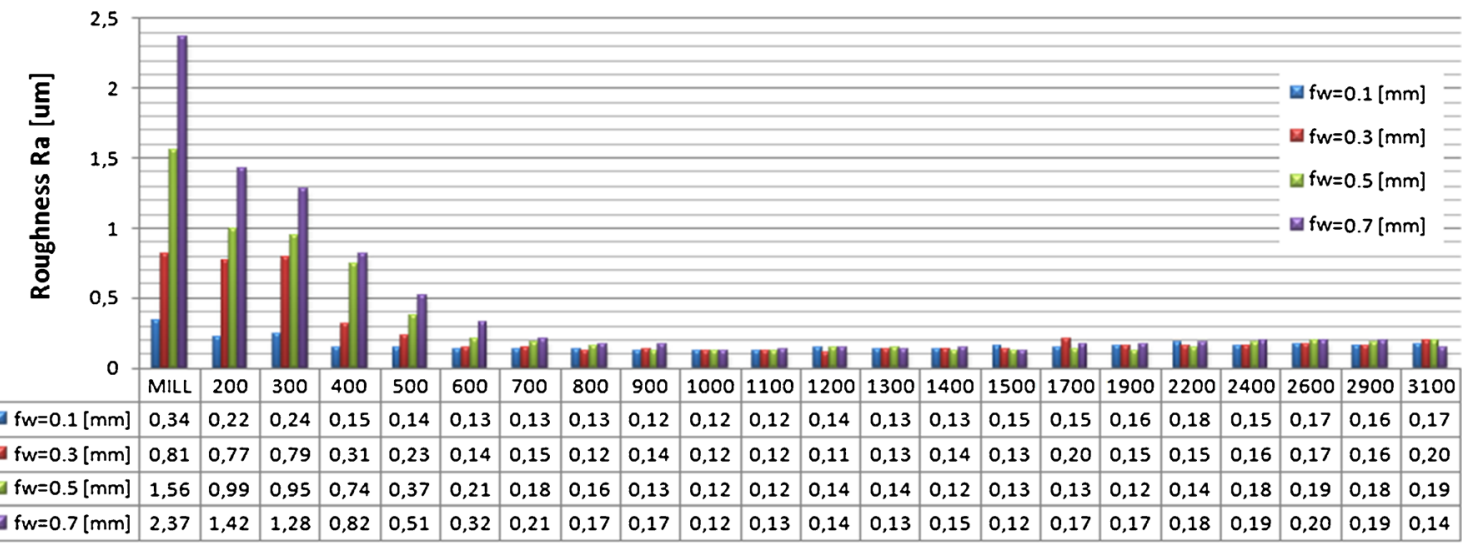

\section{Burnishing force $\mathrm{F}_{\mathrm{N}}[\mathrm{N}]$}

Fig. 2 Dependence between roughness and burnishing force $F_{N}$ and path interval $f_{w}$ [2] 
Fig. 3 Typical surface textures after milling: a after highperformance milling and $\mathbf{b}$ after high-speed milling

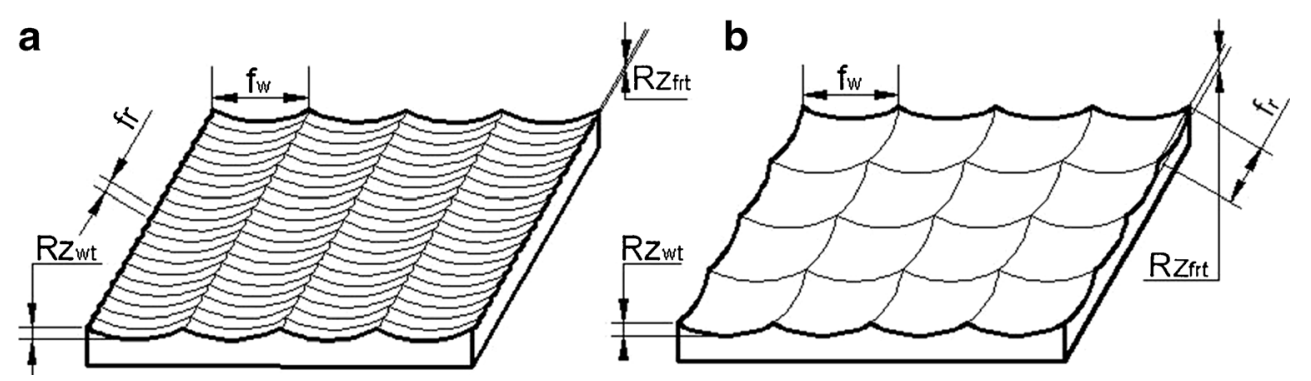

Bearing in mind the economic aspects of milling, it is rational to apply high values of parameter $\left(f_{w}\right)$, force $\left(F_{N}\right)$, and burnishing speed $\left(v_{b}\right)$.

Given the above information, some questions arise. Do the milling performances and obtained parameters for the surface geometry significantly affect the residual stress? Can high-contour burnishing be responsible for such adverse effects as spalling, crumbling, and cavitation wear in the surface layers of injection molds, matrices, and press tools?

The residual stress in the surface layer of injection molds, matrices, and press tools has a decisive role on the performance, spalling, crumbling, and cavitation wear of the forming surfaces.

\section{Kinematic-geometric model of milled surface}

The surfaces of injection molds, matrices, and press tools are usually milled with ball or torus cutters $[4,5]$. The texture of the surface depends on the CAM-generated trajectory of a cutter. Two feed directions can be distinguished (to be defined by a technologist): longitudinal feed $\left(f_{r}\right)$ and cross feed $\left(f_{w}\right)$ (Fig. 3).

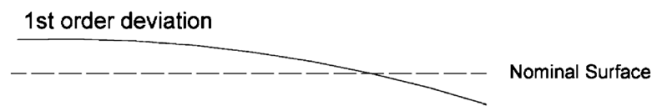

2nd order deviation

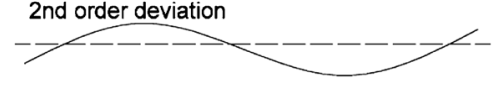

3rd order deviation

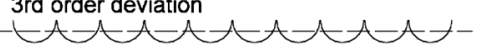

4th order deviation

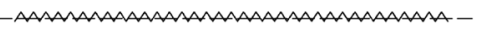

Surface roughness

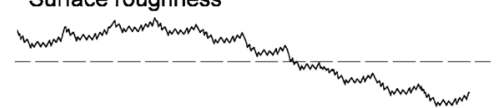

Fig. 4 Components of roughness profile
The theoretical roughness that is obtained following machining, depending on the cutter's direction, can be defined by the following:

in the longitudinal (parallel) direction to the feed direction of a cutter

$\mathrm{Rz}_{\mathrm{fit}}=\frac{f_{r}^{2}}{4 \cdot D_{\mathrm{ef}}}$

in the cross feed (perpendicular) direction to the feed direction of a cutter

$$
\mathrm{Rz}_{\mathrm{wt}}=\frac{f_{w}^{2}}{4 \cdot d_{p}}
$$

where:

$f_{r} \quad$ feed per revolution

$D_{\text {ef }} \quad$ effective diameter of a cutting tool

$f_{w} \quad$ path interval

$d_{p} \quad$ diameter of a cutting tool's insert.

To ensure smooth burnishing operations, the theoretical roughness heights after milling in both directions should be the same in both operations (Eq. 3).

$\mathrm{Rz}_{\mathrm{frt}} \approx \mathrm{Rz}_{\mathrm{wt}}$

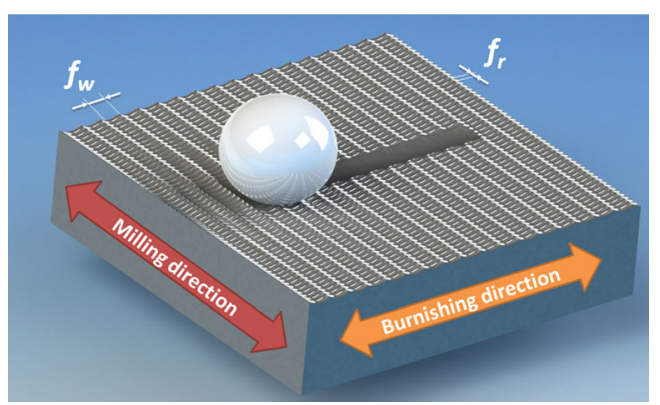

Fig. 5 Kinematics of burnishing complex spatial surface after milling 
Table 1 Properties of X42CrMo4 (35 HRC) steel

\begin{tabular}{lllll}
\hline Parameter & Symbol & Unit & $\begin{array}{l}\text { Catalogue data } \\
\text { for 20-24 HRC }\end{array}$ & $\begin{array}{l}\text { Average value in } \\
\text { tensile tests 35 } \pm \text { HRC }\end{array}$ \\
\hline Longitudinal modulus of elasticity & $\mathrm{EX}$ & $\mathrm{GPa}$ & 210 & 210.2 \\
Poisson's ratio & $\mathrm{NUXY}$ & - & 0.28 & 0.28 \\
Longitudinal modulus of elasticity & $\mathrm{GXY}$ & $\mathrm{N} / \mathrm{m}^{2}$ & $7.9 \mathrm{e}+010$ & - \\
Specific mass & $\mathrm{DENS}$ & $\mathrm{kg} / \mathrm{m}^{3}$ & 7,800 & - \\
Tensile strength & $\mathrm{SIGXT}$ & $\mathrm{GPa}$ & 1.000 & 1.046 \\
Yield strength & SIGYLD & $\mathrm{MPa}$ & 750 & 840 \\
Coefficient of thermal expansion & ALPX & $/ \mathrm{K}$ & $1.1 \mathrm{e}-005$ & - \\
Elongation & $\mathrm{A}$ & $\%$ & 14.7 & 10.86 \\
Coefficient of thermal conductivity & $\mathrm{KX}$ & $\mathrm{W} /(\mathrm{m} \cdot \mathrm{K})$ & 14 & - \\
Specific heat & $\mathrm{C}$ & $\mathrm{J} /(\mathrm{kg} \cdot \mathrm{K})$ & 440 & -
\end{tabular}

However, cross unevenness is a dominant feature of the spatial topography of a milled metal surface (Eq. 4).

$\mathrm{Rz}_{\mathrm{fit}} \ll \mathrm{Rz} \mathrm{z}_{\mathrm{wt}}$

Because of the technological parameters of the milling used to produce a surface (Fig. 3a) that meets condition (3), the machining time is substantially lengthened (low values of $f_{w}$ ). The shape of a form limits the use of cutters with large diameter inserts $\left(d_{p}\right)$. On the other hand, the material of the cutting blades does not allow the use of a feed rate $\left(f_{r}\right)$ close to the feed programmed in the CAM environment $\left(f_{w}\right)$.

A shape representation of a real milled surface consists of four fundamental components of roughness Fig. 4 [16]. Practically, when burnishing complex spatial surfaces after milling, the profile roughness components of the third order, the so-called meso-roughness, determine the final effects [2]. The meso-roughness is mainly influenced by the kinematic and geometric conditions of the milling, i.e., the diameter of cutting insert $\left(d_{p}\right)$ and cross feed $\left(f_{w}\right)$. This kind of surface was used in numerical examinations aimed at determining the magnitude and distribution of the residual stress.
Fig. 6 Tensile tests: a view of sample with extensometer and $\mathbf{b}$ tensile stress characteristics $(\sigma)$ for relative elongation $\varepsilon$

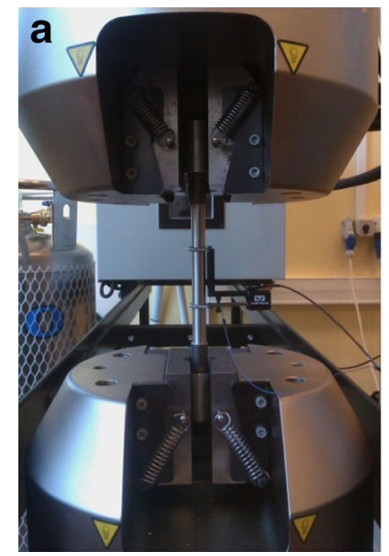

When burnishing typical complex spatial surfaces (Fig. 3a), the best effects are produced if the trajectory of a burnishing tool is perpendicular to the traces that were earlier left by the cutting tool (Fig. 5) [2, 4, 9].

\section{FEM numerical experiment}

The $42 \mathrm{CrMo} 4$ steel with $35 \mathrm{HRC}$ hardness was used in numerical investigations. The material is often used to manufacture injection forms that are used to produce plastic and rubber elements. Milling and burnishing are performed on heat-treated steel, as heat treatment improves the hardness of the steel to the above values. In order to properly map the properties of the material, we first conducted primary research.

\subsection{Examination of material's properties}

The properties of a heat-treated material are substantially different from those of the material delivered from the manufacturer (catalogue specifications (Table 1)). The properties were identified during tensile strength tests performed on an

\section{b Tensile testing with extensometer, metal sample of circular} cross-section

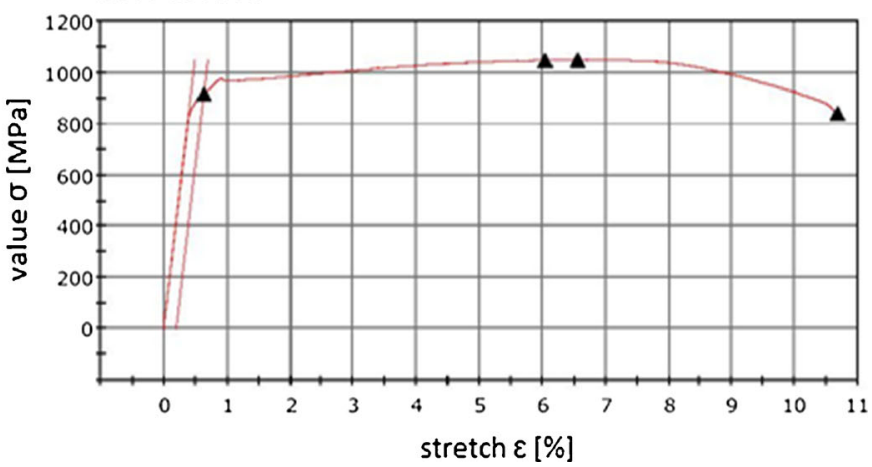



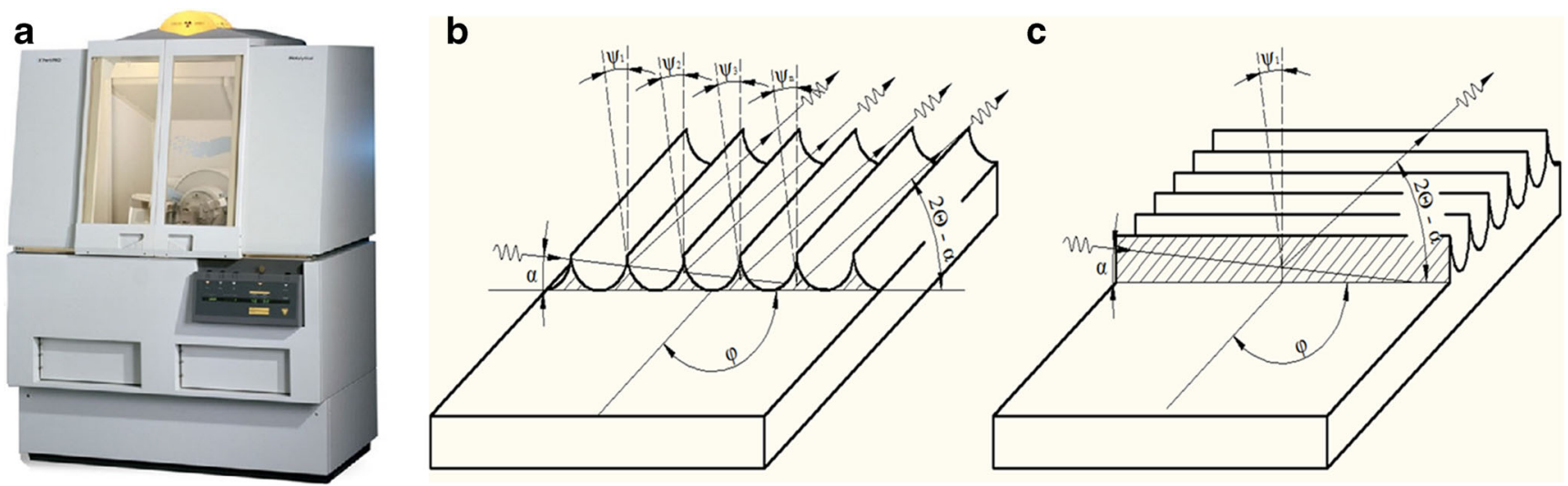

Fig. 7 Stress measurements by X-ray diffraction a X'Pert PRO diffractometer, $\mathbf{b}$ texture pattern arranged transversely to direction of X-ray beam, and $\mathbf{c}$ sample with texture parallel to direction of X-ray beam

INSTRON 8850 testing machine (Fig. 6a). As a result, the $\sigma-\varepsilon$ characteristics were determined (Fig. 6b). According to ISO 6892-1, a series of tensile tests was conducted on samples with a circular cross-section, with the following coefficients of proportionality: $k=5.65, d=14 \mathrm{~mm}$, and $L_{0}=70 \mathrm{~mm}$. Six samples made of X42CrMo4 steel (three $20 \mathrm{HRC}$ and three 35 HRC samples) were analyzed. The dispersion of the recorded parameters (longitudinal modulus of elasticity, tensile strength, and elongation) did not exceed $3 \%$. Mean values are presented in Table 1.

The heat treatment from $20 \mathrm{HRC}$ to $35 \mathrm{HRC}$ of the $\mathrm{X} 42 \mathrm{CrMo} 4$ steel significantly impacted the tensile strength, yield strength, and elongation (see Table 1 for the experimental data used in the FEM simulation).

\subsection{Methodology for measuring stress using X-ray diffraction}

The stress in the surface layer was measured using an X'Pert PRO system from Panalytical (Fig. 7a). The g-sin2 $\psi$ [17] measurement method was based on a constant angle of incidence on the beam bending plane of the X-rays inclined relative to the surface, where the angle of inclination $(\psi)$ depends on the Bragg angle $(\Theta)$ and incidence angle $(\alpha)$. At large angles $(\Theta)$, a small plane bending angle of incidence can be almost perpendicular to the sample surface, which allows fairly good results when measuring the tension of the surface layer (surface deformation). The prerequisite for conducting this type of measurement is that the surface roughness must be small (small values of $f_{w}$ and $f_{r}$ ). Where multiple $\mathrm{X}$-ray beams enter and leave the surface (metal-air) at an angle ( $\alpha$ ) (Fig. 7b), the measured values have a large dispersion. Therefore, the object of measurement was adjusted so that the surface texture was placed longitudinally to the direction of the incident beam of the X-rays (Fig. 7c).

To measure the sample with the smallest selected roughness, milling was performed with the parameters $f_{w}=0.1 \mathrm{~mm}$ and $f_{r}=0.5 \mathrm{~mm}$. The final roughness after milling was $\mathrm{Ra}=0.34$, with a value of $\mathrm{Ra}=0.12$ after burnishing [2]. The diffractometer was set to a constant value of incidence angle $\alpha=7^{\circ}$. After many attempts the surface texture was set so as to be compatible with the direction of incidence of the X-ray beam (Fig. 7c). Five measurements were performed for three different samples. The range of the measured stresses was $\sigma_{y} \approx \pm 40 \mathrm{MPa}$, a

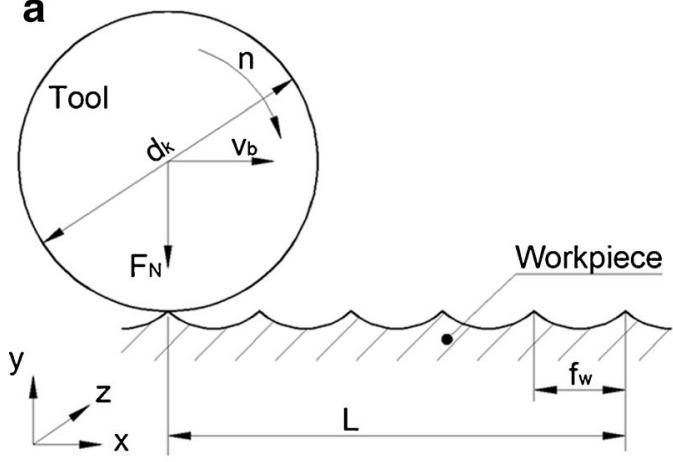

b

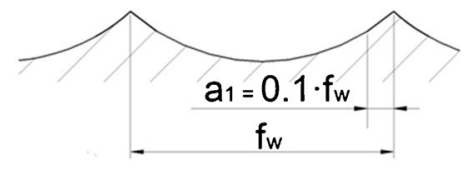

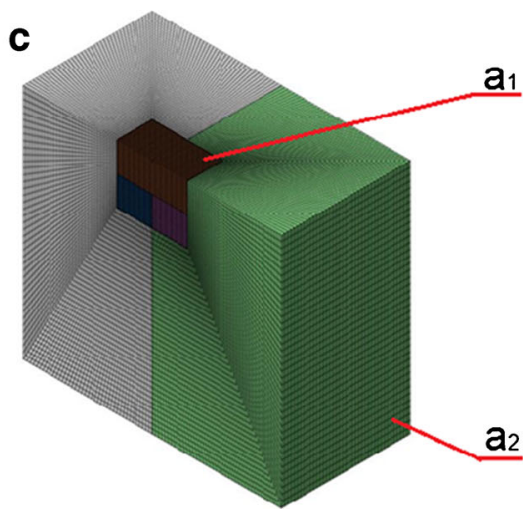

Fig. 8 Stages of numerical simulation of a ball burnishing process, $\mathbf{b}$ discretized with rectangular $a_{1}$ and $a_{2}$ elements, and $\mathbf{c}$ view of part's discretized model 
Table 2 Geometric and kinematic conditions of surface and characteristics of FEM model

\begin{tabular}{|c|c|c|c|c|c|c|c|c|c|}
\hline $\begin{array}{l}\text { Number of } \\
\text { experiment }\end{array}$ & $\begin{array}{l}f_{w} \\
(\mathrm{~mm})\end{array}$ & $\begin{array}{l}f_{r} \\
(\mathrm{~mm})\end{array}$ & $\begin{array}{l}\text { Ra after milling }{ }^{\mathrm{a}} \\
(\mu \mathrm{m})\end{array}$ & $\begin{array}{l}F_{N} \\
(\mathrm{~N})\end{array}$ & $\begin{array}{l}L \\
(\mathrm{~mm})\end{array}$ & $\begin{array}{l}a_{1} \\
(\mathrm{~mm})\end{array}$ & $\begin{array}{l}a_{2} \\
(\mathrm{~mm})\end{array}$ & $\begin{array}{l}\text { Type of } \\
\text { element }\end{array}$ & $\begin{array}{l}\text { Number of } \\
\text { element }\end{array}$ \\
\hline 1 & 0 & 0 & 0 & 1,100 & 0.5 & 0.01 & 0.05 & Hexa/8Node & 249,644 \\
\hline 2 & 0.1 & 0.5 & 0.34 & 1,100 & 0.5 & 0.01 & 0.05 & Hexa/8Node & 249,644 \\
\hline 3 & 0.3 & 0.5 & 0.81 & 1,100 & 1.5 & 0.03 & 0.1 & Hexa/8Node & 159,594 \\
\hline 4 & 0.5 & 0.5 & 1.56 & 1,100 & 2.5 & 0.05 & 0.15 & Hexa/8Node & 45,564 \\
\hline 5 & 0.7 & 0.5 & 2.37 & 1,100 & 3.5 & 0.07 & 0.2 & Hexa/8Node & 64,194 \\
\hline
\end{tabular}

${ }^{\mathrm{a}}$ Experimental results [2]

while the average value of the measured stress was $\sigma_{y} \approx-500 \mathrm{MPa}$.

\subsection{FEM model}

Investigations of a burnished surface after milling using a 2D model can lead to serious calculation errors [14]. The workpiece/tool interface varies depending on the contact point. It is also influenced by the burnishing force $\left(F_{N}\right)$ and, if motion is added, also by the geometric structure of the milled surface (parameters $f_{w}$ and $f_{r}$ ). We decided to develop a spatial model of deformation and stress. A numerical experiment was performed in the NASTRAN FX environment, considering the dynamic behaviors of elastic structures with linear damping [18]. Burnishing was divided into three parts (Fig. 8). Owing to the symmetry, the selected milled sample had a cuboid shape and the following dimensions: $70 \times 70 \times$ $35 \mathrm{~mm}$.

1. ball is pressed into a rough surface with burnishing force $F_{N}=1,100 \mathrm{~N}$

2. ball is rolled on machined surface at a length segment $\mathrm{L}$ equal to five lengths of $f_{w}$

3. ball leaves the contact zone

Because of hardware limitations, the cuboid elements in the 3D model had various sizes in the discretization mesh. The burnishing ball used for the numeric analysis had a diameter of $d_{k}=10 \mathrm{~mm}$. Practically, when heat-treated steel is roller burnished, ceramic ball heads are used (e.g., $\mathrm{ZrO}_{2}, \mathrm{Al}_{2} \mathrm{O}_{3}$ ). Ceramic materials have high hardness values of 75-80 HRC. Therefore, the ball surface was considered to be rigid and was divided using cuboid elements. Rectangular finite elements were used, which had a smaller size in the direct vicinity of the burnishing ball (the average dimension of the element is denoted with the symbol a1 in Fig. 8b). Larger rectangular elements, with the a2 size (Table 2), were used in other parts of the model. The model, divided into finite elements, is presented in Fig. 8c. Other parameters, including the size, number, and type of finite elements, are presented in Table 2. The "surface-to-surface" (one way) type was selected to model the "ball-to-workpiece" contact. The rolling resistance coefficient between the ball and the workpiece was 0.005 . On the $\mathrm{XZ}$ plane, $3^{\circ}$ of freedom were reduced. In the axial crosssection ( $\mathrm{YZ}$ plane), $2^{\circ}$ of freedom were reduced. The ball could still freely move along the Y-axis. A plane burnished sample was added to validate the experimental data. This model was designated in the numerical experiment as the first.

\subsection{Results of numerical experiment}

The deviation between the results of the numerical experiment and the experimental stress values was approximately $16 \%$. In the experiment, the surface was milled using $f_{w}=0.1$ and $f_{r}=0.5 \mathrm{~mm}$. The ceramic ball head used for burnishing had a diameter of $d_{k}=10 \mathrm{~mm}$, and the applied force was equal to $F_{N}=1,100 \mathrm{~N}$. The samples were made from X42CrMo4 (35 HRC) steel. The measured average stress value per unit volume of the material was $-500 \mathrm{MPa}$, while the simulation value was slightly lower, $-420.3 \mathrm{MPa}$. The depth of the maximum compressive stress was precisely determined in the numerical examination (Table 2). All the component values of the spatial state of residual stress were determined in the numerical experiment. Only the normal stress values for the material were analyzed in depth, in the $\mathrm{Y} \sigma_{y}$ direction (Fig. 9). The normal stress in the material (in the Y-direction) and the performance stress are both responsible for the fracture mechanics (propagation of cracks, surface spalling).

Under the conditions of the numerical experiment, the influence of the geometric structure of the surface after milling on the final effect of burnishing was noticeable.

The greatest differences were found in the tensile stress values directly on the surface (depth $=0$ ) (Table 3 ). Therefore, burnishing surfaces with high amplitude parameters for the

Fig. 9 Graphs of normal stress $\left(\sigma_{y}\right)$ a for a smooth sample; $\mathbf{b}$ for a milled sample $f_{w}=0.1$ and $f_{r}=0.5$, c for a milled sample $f_{w}=0.3$ and $f_{r}=0.5$, $\mathbf{d}$ for a milled sample $f_{w}=0.5$ and $f_{r}=0.5$, e for a milled sample $f_{w}=0.7$ and $f_{r}=0.5$ 

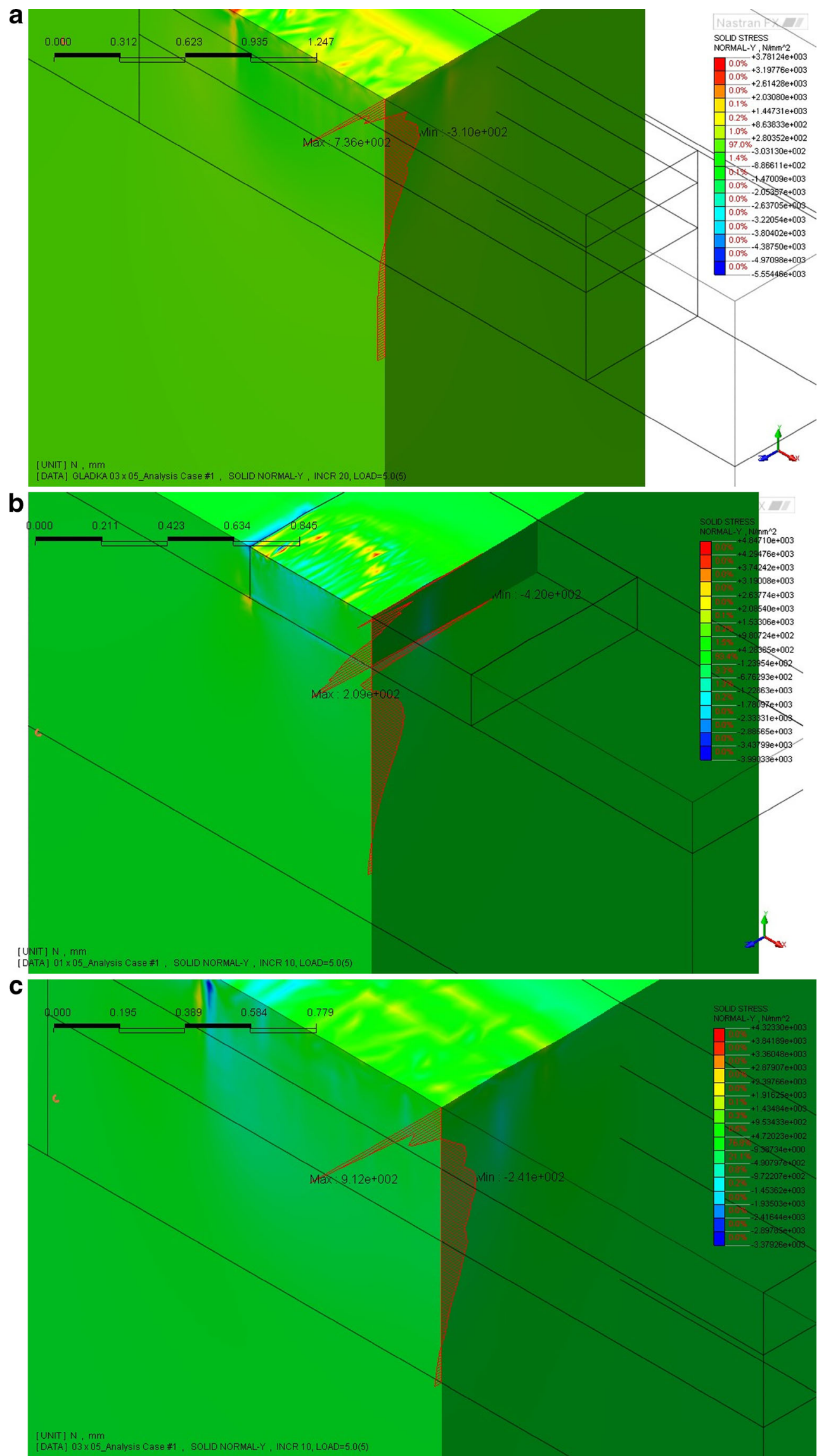


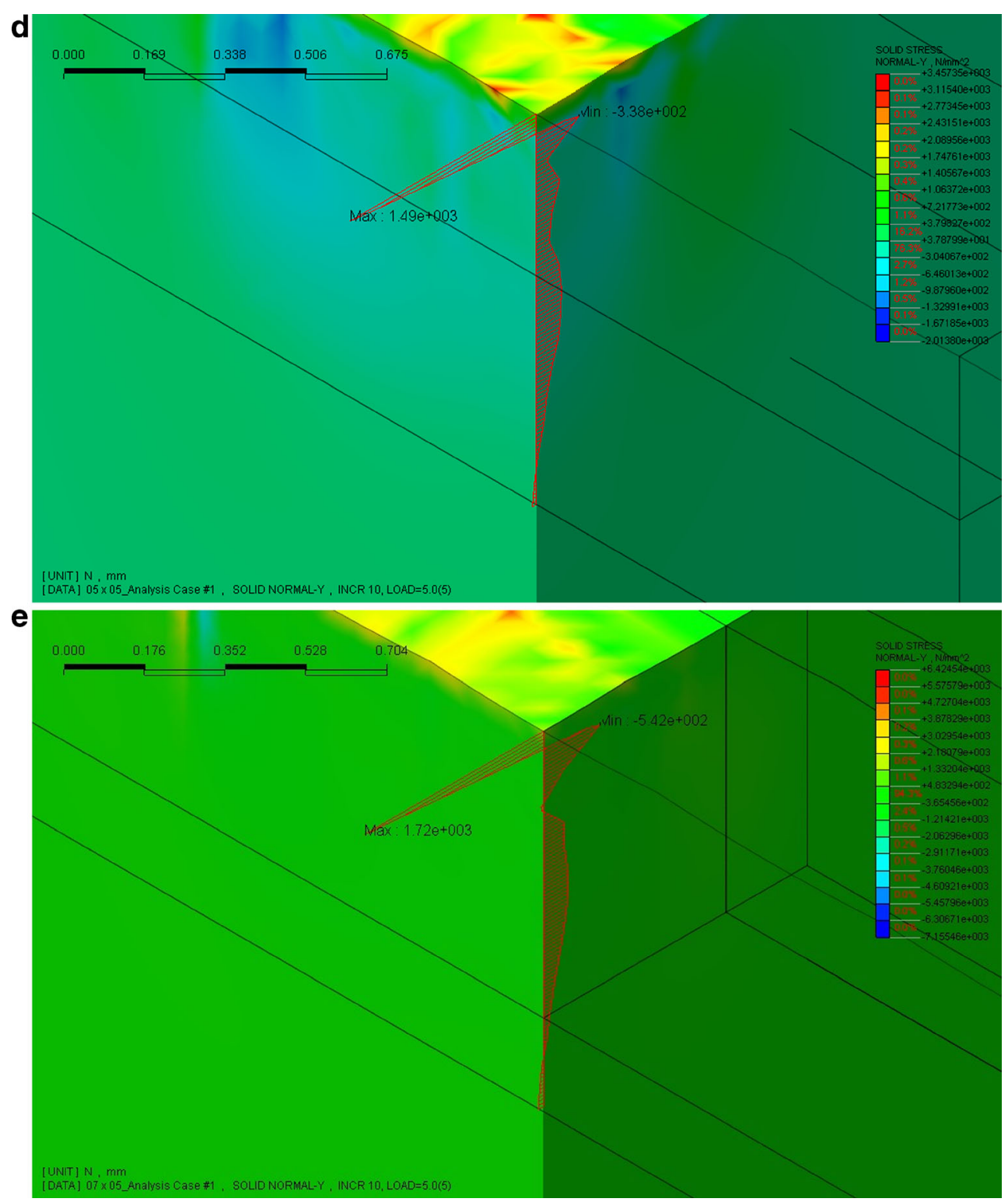

Fig. 9 (continued)

Table 3 Stress values obtained in FEM simulation

\begin{tabular}{|c|c|c|c|c|c|c|}
\hline \multirow{3}{*}{$\begin{array}{l}\text { Number of } \\
\text { experiment }\end{array}$} & \multirow[t]{3}{*}{$f_{w}$} & \multirow{3}{*}{$\begin{array}{l}\text { Average } \\
\text { measured } \\
-\sigma_{y} \\
(\mathrm{MPa})\end{array}$} & \multicolumn{4}{|c|}{ Residual stress } \\
\hline & & & Max & Depth & Max & Distance \\
\hline & & & $\begin{array}{l}-\sigma_{y} \\
(\mathrm{MPa})\end{array}$ & $\begin{array}{l}\max -\sigma_{y} \\
(\mathrm{~mm})\end{array}$ & $\begin{array}{l}+\sigma_{y} \\
(\mathrm{MPa})\end{array}$ & $\begin{array}{l}\sigma_{y} \\
(\mathrm{MPa})\end{array}$ \\
\hline 1 & 0 & - & -309.9 & 0.33 & 736.2 & $1,046.1$ \\
\hline 2 & 0.1 & -500 & -420.3 & 0.2 & 208.5 & 628.9 \\
\hline 3 & 0.3 & - & -240.7 & 0.34 & 911.6 & $1,152.4$ \\
\hline 4 & 0.5 & - & -337.6 & 0.07 & $1,488.4$ & 1,826 \\
\hline 5 & 0.7 & - & -541.9 & 0.07 & $1,722.3$ & $2,264.3$ \\
\hline
\end{tabular}

surface geometry is not recommended. Potential performancerelated damage might start on the surface, with microcracks propagating inside the material only later.

However, the high-speed burnishing of a milled surface (high values of $f_{w}$ and $f_{r}$ ) with high roughness is also favorable. An increase in the surface geometry parameters is combined with a significant increase in stress $\left(\sigma_{y}\right)$ with negative values (compressive stress). This means that additional performance-related stress (caused by a load applied to external parts or temperature) and residual stress will cancel each other. This kind of surface will endure harsher operation conditions. In this way, pitting effects can be minimized. However, the depth of the maximum residual stress $\left(\sigma_{y}\right)$ with negative values is reduced as the initial roughness increases (after milling) (Fig. 9). 


\section{Summary and conclusions}

The results of the numerical experiment were quite highly consistent with the experimental data. It may be concluded, therefore, that the FEM model of a burnished and milled surface was well developed and that it provides a good basis for further numerical examinations and experimental comparisons.

The values of stress $\left(\sigma_{y}\right)$ obtained in the simulation were slightly lower than the measured values. This might have been caused by the remaining residual stress after milling or by material hardening following dense burnishing (closely set passes of the burnishing tool). While the above factors have not been investigated, we intend to look into them in the future.

Changes in the surface roughness significantly affect the stress values after burnishing. Further research on the phenomenon is essential for a deeper insight into the mechanics of the origin and development of the stress that depends on the surface geometry parameters. Consequently, there is no danger that the surface of a workpiece may be inadvertently damaged during high-speed machining.

Burnishing a surface with substantial unevenness may cause dangerous levels of stress directly at the surface, microcrack progression, and its gradual propagation inside the material.

Further studies are required to determine the relationships between dangerous stress in the surface layer of a workpiece, its residual depth, the burnishing force, and the maximum allowable roughness height that may be burnished.

Open Access This article is distributed under the terms of the Creative Commons Attribution License which permits any use, distribution, and reproduction in any medium, provided the original author(s) and the source are credited.

\section{References}

1. El-Khabeery MM, El-Axir MH (2001) Experimental techniques for studying the effects of milling roller-burnishing parameters on surface integrity. Int J Mach Tools Manuf 41:1705-1719
2. Grochała D (2011) Nagniatanie narzędziami hyrostatycznymi powierzchni przestrzennych złożonych na frezarkach CNC, Dissertation, West Pomeranian University of Technology Szczecin http://zbc.ksiaznica.szczecin.pl/Content/24025/Praca+dokt+D.+ Grocha\%C5\%82a.pdf

3. Korzynski M, Lubas J, Swirad S, Dudek K (2011) Surface layer characteristics due to slide diamond burnishing with a cylindricalended tool. J Mater Process Technol 211:84-94

4. Lopez de Lacalle LN, Lamikiz A, Munoa J, Sanchez JA (2005) Quality improvement of ball-end milled sculptured surfaces by ball burnishing. Int J Mach Tools Manuf 45:1659-1668

5. Lopez de Lacalle LN, Lamikiz A, Sanchez JA, Arana JL (2007) The effect of ball burnishing on heat-treated steel and inconel 718 milled surfaces. Int J Adv Manuf Technol 32:958-968

6. Rodríguez A, López de Lacalle LN, Celaya A, Lamikiz A, Albizuri J (2012) Surface improvement of shafts by the deep ball-burnishing technique. Surf Coat Technol 206:2817-2824

7. Shiou FJ, Chen CH (2003) Determination of optimal ball-burnishing parameters for plastic injection moulding steel. Int J Adv Manuf Technol 3:177-185

8. Shiou FJ, Chen CH (2008) Ultra-precision surface finish of NAK80 mould tool steel using sequential ball burnishing and ball polishing processes. J Mater Process Technol 201:554-559

9. Shiou FJ, Chuang CH (2010) Precision surface finish of the mold steel PDS5 using an innovative ball burnishing tool embedded with a load cell, Precis. Engineering 34:76-84

10. Stalin JMR, Vinayagam BK (2011) Optimization of ball burnishing process on tool steel (t215cr12) in CNC machining centre using response surface methodology. Arab J Sci Eng 36:1407-1422

11. Benardos PG, Vosniakos G-C (2003) Predicting surface roughness in machining a review. Int J Mach Tools Manuf 43:833-844

12. Balland P, Tabourot L, Degre F, Moreau V (2013) Mechanics of the burnishing process, Precis. Engineering 37:129-134

13. Bougharriou A, Saï WB, Saï K (2010) Prediction of surface characteristics obtained by burnishing. Int J Adv Manuf Technol 51:205-215

14. Sartkulvanich P (2007) Determination of material properties for use in FEM simulations of machining and roller burnishing: dissertation The Ohio State University

15. Deng WJ, Xia W, Zhou ZY, Chen WP, Li YY (2004) Finite element analysis of effects of ball burnishing parameters on residual stresses. Mater Sci Forum 471-472:658-662

16. Product catalogue of ECOROLL, Werkzeugtechnologie fuer die Oberflächenveredelung, E-Publishing http://www.ecoroll.de/

17. Senczyk D (2005) Podstawy tensometrii rentgenowskiej, Wydawnictwo Politechniki Poznańskiej ISBN 83-7143234-7

18. Zienkiewicz OC, Taylor RL, Zhu JZ (2005) Finite element method its basis \& fundamentals, 6th edn. Elsevier, Butterworth-Heinemann. ISBN-13:9780750663205 